\title{
The analysis of leadership qualities of veterans of volleyball players in the training process
}

\author{
Nikolai Gogolev ${ }^{1, *}$, Semen Sabaraykin ${ }^{1}$, and Maria Glukhareva ${ }^{1}$ \\ ${ }^{1}$ North-Eastern Federal University named after M. K. Ammosov, 677027, 58 Belinsky str, Yakutsk, \\ Russia
}

\begin{abstract}
The article presents the results of a study on 5 basic control tests for the identification of leadership qualities by a veteran of volleyball players of the sports club "Sergelekh" (Yakutsk, Russia). Despite the effectiveness of the proposed technique, but additional training in technical methods is necessary, since by controlling the training process, one can reveal the leadership qualities of the veteran volleyball players and anticipate the result in sports activities, i.e. at competitions.
\end{abstract}

\section{Introduction}

Currently, sports games have determined the importance of identifying the leadership qualities of volleyball players, which are held behind the level of preparedness of those being involved. With this in mind, the present methodological recommendations describe the means of pedagogical control, control of leadership qualities, their development of special physical qualities in volleyball players, as well as a way of analyzing the level of technical preparedness achieved by them with respect to the implementation of specific in these sports technical techniques.

Our research work is devoted to the topical issue, as in rural areas of the Republic of Sakha (Yakutia) volleyball is one of the important components of the formation of health and physical self-improvement of a person, especially among the elderly. Our pedagogical experiment was attended by veterans of volleyball players of the sports club "Sergelekh" (Yakutsk, Russia).

If the trainer coach wants his/her team to have high results in performing technical and tactical actions, then he/she needs to conduct various types of control, consisting of effective tests, which will have to be performed by the trainees. It should take into account the age of the veterans of volleyball, their sex, and physical fitness. Without taking into account and controlling the instructor, the coach will not be able to notice any progress in the preparation, these results will be manifested in gaming, training, and competitive activities. If a veteran volleyball player cannot perform an attacking blow, then he/she must perform just high jumps and weight-lifting jumps, strike the ball into the wall, into the floor, but the instructor coach corrects the mistakes made and points out how to do better without harm to health. That's why we need ongoing monitoring and accounting in the training of the veterans of volleyball. The effectiveness of increasing the skill of veterans of

* Corresponding author: gogolev_ne@ inbox.ru 
volleyball depends, to a large extent, on the rational construction of general and special training at all stages of the training process.

Thus, the rational use of technical means by which the instructor trainer can take into account and control the training allows the following: to more effectively solve problems of practical implementation of training tasks and most purposefully manage the training process of veterans of volleyball players; to significantly expand the range of means and methods to improve the level of technical and physical training of veterans of volleyball players; to maintain a high degree of conjugation of special exercises with the basic competitive movements; to more purposefully develop specific muscle groups; to repeatedly perform difficult-coordination exercises in a given mode; to clearly dose rate, power, and speed-strength loads.

\section{Research design}

Despite the significant number of works showing the effectiveness of the use of technical means, in the training of veterans and in the formation of leadership qualities, their application in practice has not yet been properly disseminated.

However, it is certain that in recent years coaches/instructors have shown increasing interest in the use of technical means in the training process of training veterans of volleyball players.

The purpose of the research is to justify the importance of monitoring and recording in the training process of veterans of volleyball players in identifying leadership qualities.

The research was organized in the following way. The team of veterans was preparing for regional and republican competitions for three months. At this time, in the training sessions and competitions as a result of the control, we conducted our studies.

At the first stage of the study, we observed the training process of veterans of volleyball players, their technical and physical training necessary to achieve a sporting result in competitions.

In the lesson, the veterans carried out certain elements of technical and tactical actions, imitating elements. Behind their actions the instructor watched, if necessary, then made adjustments or suggested the game combinations that veterans performed and applied in the training game in the competitive activity. The lesson was accompanied by the control over the technical and tactical training of veterans of athletes. After two classes, we looked through and analyzed with the volleyball players on the video recordings of the training sessions, which were made by the instructor to identify mistakes in the technical methods admitted by the veterans of volleyball players. It is necessary to do this so that the veterans of volleyball players could see e their mistakes in the technique and correct them in subsequent lessons.

The control serves to obtain information about the current state of the process of training veterans of volleyball. The main types of control were the following: stage, current, and operational. The main form of control was pedagogical.

In the course of pedagogical control, necessary information was obtained, on the basis of which the effectiveness of the system of pedagogical influences was assessed. Its tasks included: implementation of training plans and their adjustment, assessment of the effectiveness of the means and methods used, training tasks, training sessions, micro cycles, medium cycles, etc.; choice of indicators and justification of benchmarks for assessing the preparedness of the veterans of volleyball players by basic parameters; identification of the dynamics of sport achievements (indicators of competitive activity); and identification and selection of promising volleyball players.

At the second stage of the study, we conducted control tests on 5 basic techniques, which, in our opinion, were used by the veteran volleyball players constantly during 
training and competitions. In the study, we used the technique proposed by A. A. Demchishin and B. S. Pilipchuk in "Preparation of Volleyball Players," which included the upper gear of the ball, the lower gear of the ball, the attacking kick, the blocking of the ball, and the upper direct feeding of the ball.

The research was carried out on the basis of the North-Eastern Federal University named after M. K. Ammosov (Yakutsk, Russia). The age range of the veteran volleyball players was 38-45 years. To identify leadership qualities, 11 peoplewere trained during the period from September to November 2017, because they were preparing for competitions at different levels.

The method of mathematical statistics was used in the study. They were used for processing and analyzing the received data on a PC Pentium using Microsoft Excel 7.0 software, for which small sampling techniques were used. In doing so, the main statistical indicators were calculated, such as: the arithmetic mean $\mathrm{X}$ and the sum $\Sigma$ of an individual measurement value.

\section{Results and Discussion}

Table 1 presents the results of the test "Upper transfer of the ball over yourself (out of 20 possible actions)."

Table 1. Upper transfer of the ball over yourself (out of 20 possible actions).

\begin{tabular}{|c|c|c|c|c|c|c|}
\hline $\begin{array}{c}\text { Participants in } \\
\text { the experiment } \\
\text { code }\end{array}$ & 1 lesson & 2 lesson & 3 lesson & 4 lesson & 5 lesson & $\boldsymbol{\Sigma}$ \\
\hline B1 & 21 & 19 & 18 & 20 & 17 & $\mathbf{9 5}$ \\
\hline B2 & 20 & 20 & 21 & 20 & 21 & $\mathbf{1 0 2}$ \\
\hline B3 & 19 & 20 & 12 & 15 & 15 & 81 \\
\hline B4 & 15 & 18 & 18 & 20 & 14 & 85 \\
\hline B5 & 17 & 19 & 17 & 15 & 15 & 83 \\
\hline B6 & 18 & 11 & 16 & 15 & 19 & 79 \\
\hline B7 & 11 & 15 & 13 & 16 & 11 & 66 \\
\hline B8 & 17 & 19 & 18 & 19 & 20 & 93 \\
\hline B9 & 10 & 15 & 14 & 18 & 20 & 77 \\
\hline B10 & 17 & 15 & 18 & 13 & 16 & 79 \\
\hline B11 & 16 & 18 & 15 & 16 & 20 & 85 \\
\hline X & 16 & 17 & 16 & 17 & 17 & 84 \\
\hline
\end{tabular}

As can be seen, the standard of 20 upper gears of the ball over oneself, the results are not stable, a good result is shown in participants of pedagogical experiment B1, B2, and B8. Some people require additional training. The reasons for the unstable results are the inaccuracy of the upper gears in pairs.

Table 2 presents the results of the study with another exercise.

Table 2. Lower transfer of the ball over yourself (out of 20 possible actions). 


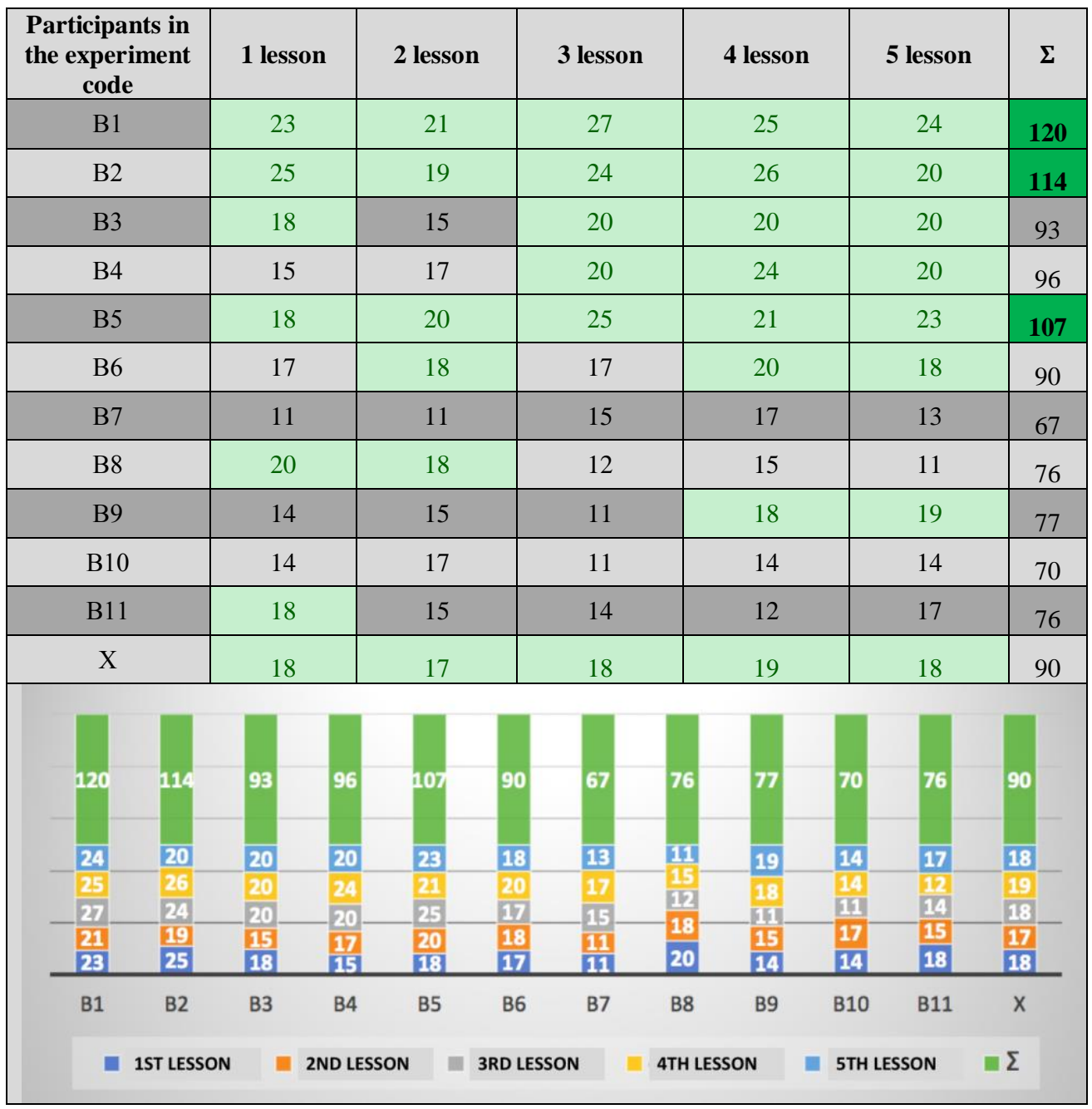

The standard is 20 lower gears above the ball. Transmission must be carried out to a height of -1.5 meters. Veterans showed average results, but many mistakes were made due to incorrect position of the hands. Progressive results during the experiment were shown by 3 participants, namely $\mathrm{B} 1, \mathrm{~B} 2$, and $\mathrm{B} 5$.

Table 3. Top direct feed (out of 20 possible actions).

\begin{tabular}{|c|c|c|c|c|c|c|}
\hline $\begin{array}{c}\text { Participants in } \\
\text { the experiment } \\
\text { code }\end{array}$ & 1 lesson & 2 lesson & 3 lesson & 4 lesson & 5 lesson & $\boldsymbol{\Sigma}$ \\
\hline B1 & 11 & 15 & 17 & 16 & 18 & 77 \\
\hline B2 & 18 & 16 & 20 & 20 & 17 & 91 \\
\hline B3 & 14 & 13 & 11 & 19 & 17 & 74 \\
\hline B4 & 16 & 20 & 12 & 15 & 15 & 78 \\
\hline B5 & 19 & 14 & 17 & 20 & 17 & 87 \\
\hline B6 & 15 & 18 & 17 & 11 & 20 & 81 \\
\hline B7 & 17 & 20 & 11 & 8 & 16 & 72 \\
\hline
\end{tabular}




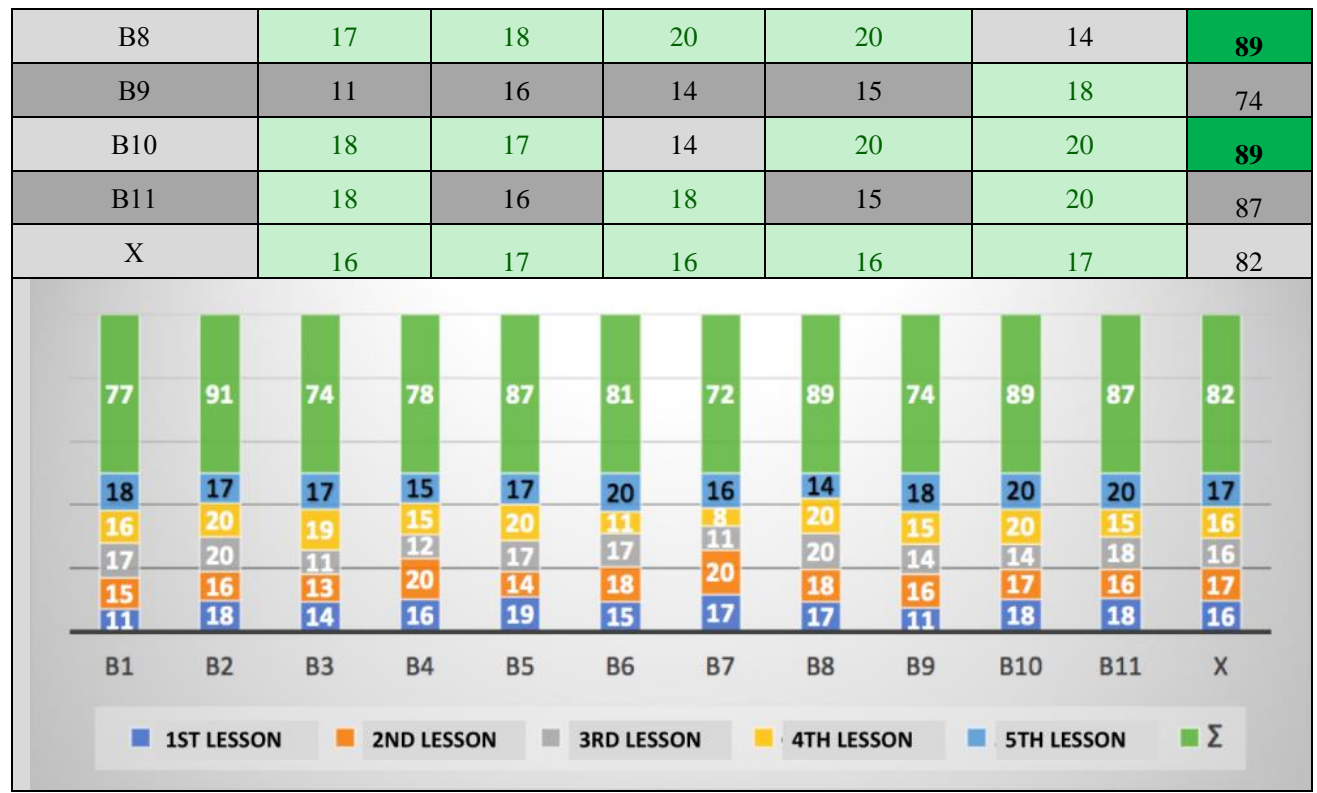

Performance standard: it is necessary to perform 20 top straight feeds in the field. Some of those occupying a lot of feeds got off-site, and some performed a very strong pitch; therefore, it is necessary to improve the technique, one can use an individual approach. In this test, progressive results were shown by participants being coded as B2, B8, and B10.

Table 4. Attacking blow (any of 15 possible actions).

\begin{tabular}{|c|c|c|c|c|c|c|}
\hline $\begin{array}{c}\text { Participants in } \\
\text { the experiment } \\
\text { code }\end{array}$ & $\mathbf{1}$ lesson & $\mathbf{2}$ lesson & 3 lesson & 4 lesson & 5 lesson & $\boldsymbol{\Sigma}$ \\
\hline B1 & 10 & 12 & 9 & 12 & 11 & 54 \\
\hline B2 & 14 & 11 & 11 & 12 & 15 & $\mathbf{6 3}$ \\
\hline B3 & 8 & 10 & 10 & 10 & 13 & 51 \\
\hline B4 & 10 & 12 & 9 & 10 & 10 & 51 \\
\hline B5 & 13 & 10 & 12 & 13 & 14 & 62 \\
\hline B6 & 11 & 13 & 10 & 10 & 14 & 58 \\
\hline B7 & 9 & 11 & 11 & 15 & 7 & 53 \\
\hline B8 & 14 & 12 & 15 & 13 & 14 & 68 \\
\hline B9 & 11 & 9 & 15 & 10 & 11 & 56 \\
\hline B10 & 7 & 10 & 14 & 9 & 10 & 50 \\
\hline B11 & 14 & 11 & 14 & 15 & 15 & $\mathbf{6 9}$ \\
\hline X & 11 & 11 & 12 & 12 & 12 & 58 \\
\hline
\end{tabular}




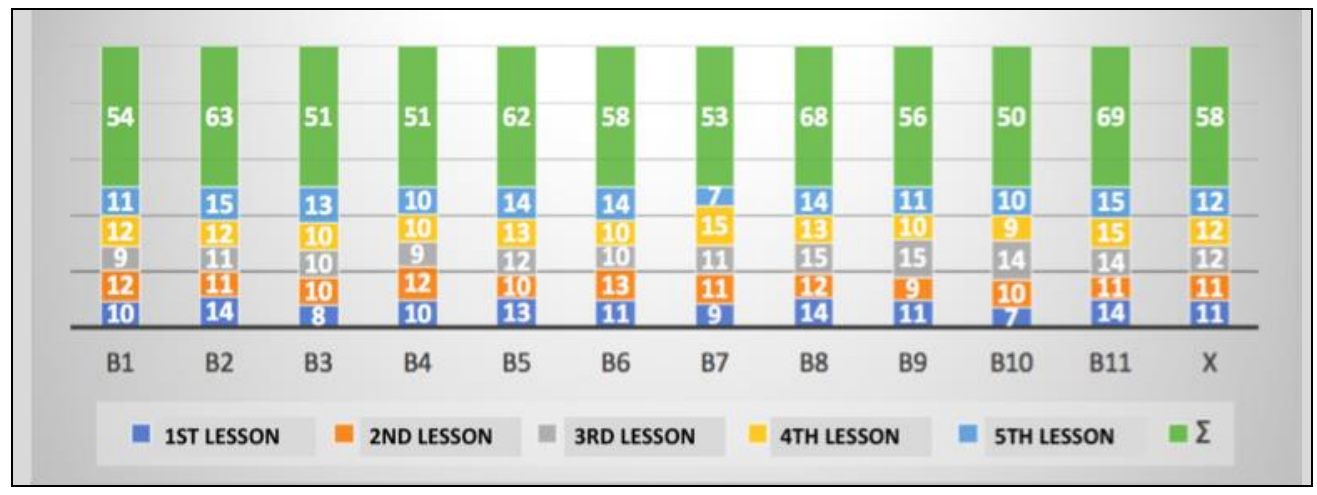

Performing 15 attempts, there were 12 attacking blows, but with a hit in the pad. The results were good, but preparation was still necessary, since the attacking blow is the basis in the tactics of attack during the game. If there were good top gears, then there would. be a result in the technique of attack. In this test, the best results were shown by B2, B8, and B11.

Table 5. Blocking the ball (out of 10 possible actions).

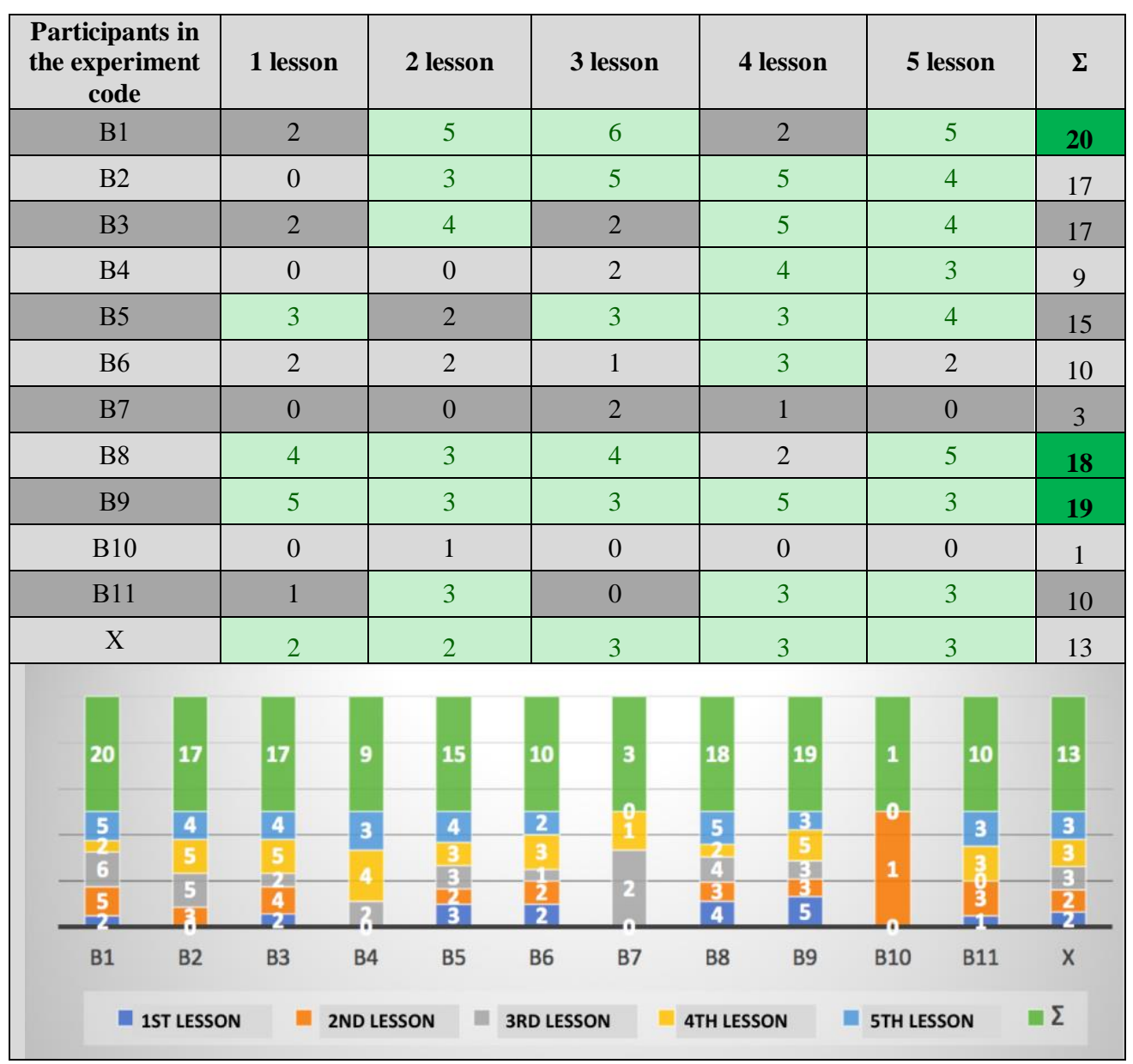


It was necessary to complete 10 attempts in 1 lesson, i.e. perform blocking the ball. The results were weak, with additional training one needed to perform jumping on the rope, jumping out of the deep squat, and the squat with a bar (40-50\%). Good results during the pedagogical experiment were shown by the participants coded as B1, B8, and B9.

\section{Conclusion}

Thus, according to the results of the test, we conclude that the veterans showed fairly good results; the leaders of volleyball players (B1, B2, B5, B8, B9, B10, and B11) were revealed; and the participant (B8) was identified to improve the techniques during the pedagogical experiment. But additional training in technical methods is necessary, since by controlling the training process, we can reveal the leadership qualities of the veteran volleyball players and anticipate the result in sports activities, i.e. at competitions.

\section{References}

1. A. A. Demchishin, B. S. Pilipchuk, Training of volleyball players (Health, Kiev, 1979)

2. A. V. Zhurin, Fundamentals of volleyball techniques: Textbook. -method. allowance (Moscow State University named after Ivan Fedorov, Moscow, 2014) 